\title{
Application of specialized exercises for the development of strength qualities of future air transport safety specialists
}

\author{
Inessa Rodionova $^{1}{ }^{*}$, Vladimir Shalupin ${ }^{1}$ \\ ${ }^{1}$ Moscow State Technical University of Civil Aviation, Russia
}

\begin{abstract}
The article deals with the problems of finding the most rational method of developing the strength qualities of students of civil aviation universities, and in particular the direction of training "Air Navigation" (ATC), by optimal distribution of the time of power loads for the formation of professional training of future specialists of airfield services. In the structure of such training, a special place is occupied by power qualities, which are most important for specialists of airfield services, who ensure the safety of air transport. Strength training not only increases the body's resistance to the effects of adverse environmental factors and strengthens the immune system, but also optimizes the functional state of the body. However, the issues of the development of strength abilities with the use of time indicators in the distribution of specialized loads are currently insufficiently studied and do not have a scientific basis in the general system of physical training of students of educational institutions of civil aviation. In the study performed on students, the search for optimal methods for the development of strength qualities was conducted by changing the time indicators in the distribution of specialized loads. Students performed strength and speed-strength exercises with high intensity and subjective power of effort, as well as cyclic exercises that require endurance when they are performed repeatedly. These exercises were considered by us as complex means of forming motor qualities. The studied main indicators of strength qualities allowed us to determine the main vector of building classes for future specialists in the field of training "Air Navigation" (ATC) and the means of controlling the functional activity of those involved. The experimentally based methodology for the development of power qualities is recommended for use in the educational process of educational institutions of civil aviation.
\end{abstract}

Relevance. "At the present stage of the development of society, 80-90\% of people of working age experience a lack of physical activity" [1]. This situation determines the need for versatile training of future specialists in various fields. This also applies to civil aviation specialists, who play a special role in the life of society. "At present, alarming data on the

\footnotetext{
*Corresponding author: rodiinna@mail.ru
} 
systematic deterioration of the health of the younger generation, a decrease in the level of physical and functional fitness of students are becoming common" [2].

In recent years, the relevance of this problem is associated with the discrepancy between the level of physical fitness of employees of the aviation industry and the professional requirements. "Despite the fact that the air traffic control system is constantly being improved, the person was and remains the main and most vulnerable link in ensuring air traffic" [3]. This is a cause for concern. "In this regard, an important role is to ensure the necessary level of professional training of future specialists of air traffic control (ATC) of civil aviation, including physical fitness, fitness, performance, development of professionally important qualities (PIQ) and psychomotor abilities" [4]. All these professionally important qualities are formed in physical education classes. "The use of training sessions in the disciplines of physical culture to increase readiness for extreme situations is one of the most important components of the formation of motivation and conscious attitude to physical culture in the higher education system" [5].

The literature has accumulated a lot of information about the methods of developing physical qualities and motor skills based on strength abilities. Especially relevant is the development of strength or strength abilities for specialists of airfield services that ensure the safety of air transport. This is especially important when developing the professional skills of aviation industry specialists. The development of strength abilities helps to strengthen health, develop vital qualities, increases the body's resistance to the effects of adverse environmental factors, strengthens the immune system, optimizes the functional state of the body, reveals the psychological characteristics of a person.

In the work programs of educational institutions of civil aviation, strength training takes a priority place and is one of the leading means of developing physical qualities that ensure effective solution of tasks of various motor activities. This also applies to individual methods. "The structure and content of the process of physical training of students based on crossfit have proven their effectiveness in improving the functional and physical condition of students" [6].

The strength abilities of a student in the educational process are considered as the ability to resist the influence of the external environment through muscular efforts that provide static tension - without reducing the length of the muscle fibers and dynamic tension - by changing the shape and length of the muscle fibers.

"There are the following types of strength or power abilities: maximum strength, speed power, and power endurance. The dominant role in their manifestation is played by the activation of the processes of muscle tension, stimulated externally by an object or other burden" [7].

A well-chosen method of developing a person's strength abilities helps to strengthen the body, improve performance, develop physical qualities and motor skills.

However, the issues of the development of strength abilities with the use of time indicators in determining specialized loads are currently insufficiently studied and have no scientific basis in the general system of physical training of students of educational institutions of the civil aviation.

"The optimal value of the training load in academic physical education classes at the university should be determined taking into account the level of strength training of students" [8].

As practice shows, the use of individual methodological techniques for the development of power abilities is not effective enough and is fragmentary. This does not fully provide the necessary methodological techniques for the effective development of the motor qualities of future civil aviation professionals.

There is also no common opinion of specialists of physical culture and sports about the method of developing strength abilities depending on the time indicators of training loads. 
Recently, the search for the most effective methods of applying specialized loads for the development of strength abilities of students of the "Air Navigation" training direction was mainly determined by the conditions of trainee's activity, the most rational ratio of the time allocated for the development of strength endurance, speed strength and maximum strength abilities.

This process depends on such factors as the adaptive characteristics of the body, the likely periods of fatigue and the most optimal manifestations of performance.

The purpose of the study was to determine the most rational method of developing the strength abilities of students by a reasonable distribution of time between the power characteristics of specialized loads in the training of students of civil aviation universities.

Organization and methods of research. The research involved second-year students of the Moscow State Technical University of Civil Aviation (MSTU CA) of the Department of Air Transport Control (DATC): the first experimental group (1 EG) - ATC 2-1, the second experimental group (2 EG) - ATC 2-2, the control group (CG) - ATC 2-3 in the number of 67 people.

The English expert J. Honeybourne together with co-authors divided the physical exercises into groups:

1) "strength and speed-strength exercises with high intensity and subjective power of effort;

2) cyclic exercises that require endurance when performed repeatedly;

3 ) coordination exercises that manifest themselves in the conditions of a certain program of movements;

4) exercises that require a complex manifestation of physical qualities in the conditions of constantly changing modes of motor activity, situations and forms of action" [9]. Based on this classification, we used the exercises of the first and second groups as the most comprehensive means for the formation of motor skills, which can significantly improve the quality and reliability of professional activities of future specialists in the field of training "Air Navigation" (ATC).

Classes were held in the gym of the university according to a specially developed program with a change in the number of physical exercises performed of a strength and speed-strength nature. For the development of strength abilities, the method of circular training was used, including physical exercises of strength orientation on sports equipment. The peculiarity of circular training in the experimental groups was that the time and the ratio of the application of loads in different groups were implemented in different ways. Classes were held twice a week for 90 minutes. A total of 26 classes were conducted during the experiment.

In the first experimental group (1 EG), when conducting classes, from 50 to $70 \%$ of the total time spent on performing exercises for the development of speed and strength abilities was given.

In the second experimental group (2 EG), on the contrary, $50-70 \%$ of the total training time was used cyclic exercises for the development of strength endurance.

In the control group (CG), the time allotted for performing physical exercises for the development of speed-power and strength abilities was distributed in accordance with the work program of civil aviation educational institutions in the field of training "Air Navigation" (ATC).

We also studied the emotional response to physical activity using the psychological test "Well-being, activity, mood" (WbAM). "The sum obtained on each scale is in the range from 10 to 70 points and allows us to identify the functional state of an individual at a given time according to the principle: $<30$ points - low score; 30-50 points-average score; $>50$ points — high score" [10]. 
The results of the study. For two months, students of both EGs performed exercises of the corresponding orientation. After 12 training sessions, we performed the first control cross-section of strength development indicators. In all subjects of the experimental groups, it had approximately the same level.

After the second control section, after 24 classes, the test was performed using the WbAM test. The control data obtained were systematized and presented in Tables 1, 2.

Table 1. Analysis of indicators of strength tests among students of the first experimental group under the influence of load

\begin{tabular}{|c|c|c|c|}
\hline \multirow{2}{*}{$\begin{array}{l}\text { Exercises (tests) to control } \\
\text { speed and strength training }\end{array}$} & \multicolumn{3}{|c|}{ First experimental group } \\
\hline & $\begin{array}{c}\text { Data at the } \\
\text { beginning of the } \\
\text { experiment }\end{array}$ & $\begin{array}{l}\text { control data after } \\
12 \text { trainings }\end{array}$ & $\begin{array}{c}\text { control data after } \\
26 \text { trainings }\end{array}$ \\
\hline $\begin{array}{c}\text { Lifting the torso from the } \\
\text { starting position lying on the } \\
\text { back (number of times per } 1 \\
\text { min.) }\end{array}$ & 29,49 & 38,22 & 48,49 \\
\hline $\begin{array}{l}\text { Complex strength exercise } \\
\text { (number of times per } 1 \text { min.) }\end{array}$ & 34,17 & 41,67 & 53,49 \\
\hline $\begin{array}{l}\text { Starting position normal stand } \\
\text { position.- burpee - hand on the } \\
\text { ground - burpee- normal stand } \\
\text { position } \\
\text { (Number of times per } 1 \mathrm{~min} \text {.) }\end{array}$ & 17,23 & 23,11 & 31,86 \\
\hline
\end{tabular}

Table 2. Analysis of indicators of strength tests among students of the second experimental group under the influence of load

\begin{tabular}{|c|c|c|c|}
\hline Exercises (tests) to control & \multicolumn{3}{|c|}{ Second experimental group } \\
\cline { 2 - 4 } & $\begin{array}{c}\text { Data at the } \\
\text { beginning of the } \\
\text { experiment }\end{array}$ & $\begin{array}{c}\text { control data after } \\
\mathbf{1 2} \text { trainings }\end{array}$ & $\begin{array}{c}\text { control data after } \\
\mathbf{2 6} \text { trainings }\end{array}$ \\
\hline $\begin{array}{c}\text { Flexion and extension of the } \\
\text { arms }\end{array}$ & 38,20 & 44,01 & 51,43 \\
$\begin{array}{c}\text { lying down on the ground } \\
\text { (number of times) }\end{array}$ & 13,28 & 16,14 & 18,12 \\
\hline $\begin{array}{c}\text { Pull-up on the crossbar (number } \\
\text { of times) }\end{array}$ & 19,45 & 25,11 & 32,59 \\
\hline $\begin{array}{c}\text { Lifting the legs to an upright } \\
\text { position from the starting } \\
\text { position lying on the back } \\
\text { (number of times) }\end{array}$ & & & \\
\hline
\end{tabular}

We gave all three groups the task to pass online testing using the WbAM psychological test (Table 3).

Table 3. Indicators of changes in the state of the three tested groups after physical training

\begin{tabular}{|c|c|c|c|}
\hline WbAM test indicators & $1 \mathrm{EG}$ & $2 \mathrm{EG}$ & $\mathrm{CG}$ \\
& $\begin{array}{c}12 \text { trainings/ } \\
26 \text { trainings }\end{array}$ & $\begin{array}{c}12 \text { trainings/ } \\
26 \text { trainings }\end{array}$ & $\begin{array}{c}12 \text { trainings/ } \\
26 \text { trainings }\end{array}$ \\
\hline $\mathrm{Wb}-$ Well-being (points) & $45,76 / 57,45$ & $39,33 / 46,11$ & $34,17 / 38,55$ \\
\hline $\mathrm{A}-$ activity (points) & $47,11 / 58,35$ & $32,19 / 42,75$ & $38,31 / 44,54$ \\
\hline $\mathrm{M}-$ mood (points) & $49,45 / 67,12$ & $36,15 / 44,13$ & $44,48 / 50,43$ \\
\hline
\end{tabular}

As can be seen from these tables, after passing two tests, all the indicators of the first EG significantly improved. This, apparently, is due to the fact that speed-strength work not only gives a positive training effect, but also improves the emotional state of the students. 
In the second EG, all current conditions improved slightly due to adequate physical activity. At the same time, there was no significant increase in all physical indicators. Apparently, cyclic exercises require significant moral and volitional efforts, and not all students do it easily and with the necessary mood.

In the control group, the performance of the WbAM test improved compared to the first test. This is due to the fact that regular physical activity has a generally positive effect on the psychophysiological state of students.

Conclusions. The main indicators of students ' strength abilities studied by us allowed us to determine the main vector of building classes for future specialists in the field of training "Air Navigation" (ATC), to determine the mechanism and means of controlling the functional activity of the body of students, to determine the ability to maintain it at a high adequate level.

The results of the work confirm the distribution of load indicators for the effective development of strength abilities. The practical implementation of experimental studies proves the correctness of the direction of the proposed methodology and the distribution of physical loads, which expediently affect the further professional activities of future specialists in the field of training "Air Navigation" (ATC).

Based on the conducted experiment, it can be stated that the distribution of the load parameters of the exercises performed for the development of strength abilities is optimally carried out by the method of circular training.

The experimentally based methodology for the development of strength qualities can be used in the educational process of educational institutions of civil aviation, as well as in elective classes and sports training.

The applied methodology contributes to improving the quality and reliability of professional activities of future specialists in the field of training "Air Navigation" (ATC).

Nevertheless, the problem of developing strength as a physical quality remains one of the most pressing problems of physical culture and sports in terms of improving the professional training of future civil aviation workers, especially specialists of airfield services.

\section{References}

1. M.N. Komarov, S.Yu. Zavalishina, A.A. Karpushkin, A.V. Malyshev, E.S. Kumantsova, Indian Journal of Public Health Research \& Development, Rehabilitation Potential of Physical Activity Complex with Elements of Sports and Health Tourism in Case of Dysfunction of the Cardiovascular System in Adolescence Vol.10, No.10, pp. 1814-1818 (2019)

2. V.Yu.Volkov, L.M. Volkova, N.G. Lutchenko, Theory and practice of physical culture, Electronic textbook on the discipline "Physical culture" No. 7, pp. 33-36, (2014)

3. V.I. Shalupin, I.A. Rodionova, D.V. Romanyuk, Theory and practice of physical culture, Application of the complex of psychophysical training and gymnastic exercises in the training of future civil aviation specialists, No. 10, pp. 25-26, (2019)

4. D.V. Morschinina, V.V. Karpushin, V.I. Shalupin, Scientific Bulletin of MSTU CA, Value aspects of professionally applied physical training in the process of training of civil aviation specialists, No. 192, pp.130-33, (2013)

5. L.M. Stolyar, O.N. Loginov, E.V. Lyubina, T.I. Makarenkova, V.V. Averyasov, Theory and practice of physical culture, Motivational factors that increase interest in physical education among students, No. 8, pp. 83-88, (2018)

6. D.A. Kokorev, O.V. Vezenitsyn, D.V. Vyprikov, I.M. Bodrov, Theory and practice of physical culture, Structure and content of the process of physical training of students based on crossfit, No. 9, pp. 19-21, (2017)

7. T. Bompa, K. Buzzicelli, Periodization of sports training, (Sport, 385 p., 2016) 
8. Yu. I. Lyutashin, Methodology of complex development of power abilities of university students by means of athletic gymnastics. Autoref. diss. ... PhD in Pedagogy, 24 p., (2010)

9. J. Honeybourne, M. Hill, H. Moors, Advanced physical education \& sport, (London: Stanley Thornes Publishers Ltd. - 286 p, 1996)

10. Practical Psychology Magazine Experimental Psychic [online], - free access: https://experimental-psychic.ru/test-san/, (15.04.2021) 